\title{
Artigo Original / Original Paper \\ Piper (Piperaceae) do Parque Estadual da Serra da Tiririca, Niterói / Maricá, RJ, Brasil
}

Piper (Piperaceae) from Serra da Tiririca State Park, Niterói / Maricá, RJ, Brazil

\author{
George Azevedo de Queiroz ${ }^{1,4,5}$, Ana Angélica Monteiro de Barros ${ }^{2}$ \& Elsie Franklin Guimarães ${ }^{3}$
}

\begin{abstract}
Resumo
O gênero Piper possui distribuição pantropical, apresentando cerca de 2.000 espécies no mundo. É considerado um dos dez maiores gêneros neotropicais de Magnoliidae, e o maior em Piperaceae. O estudo foi realizado no

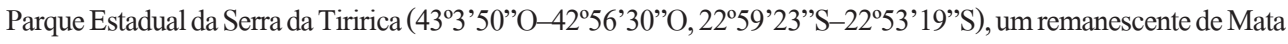
Atlântica (Floresta Ombrófila Densa Submontana), localizado na divisa dos municípios de Niterói e Maricá (RJ), com o objetivo de levantar as espécies do gênero presentes na área. Foram realizadas coletas de plantas férteis no período de 2011 a 2017 e analisadas as exsicatas dos herbários FCAB, HB, R, RB, RBE, RBR, RFA, RFFP e do banco de dados virtual SpeciesLink. Na área foram encontrados 12 espécies: P. aduncum, P. amalago, P. amplum, $P$. anisum, $P$. arboreum var. arboreum, $P$. arboreum var. hirtelum, Piper corcovadensis var. corcovadensis, $P$. divaricatum, $P$. hoffmannseggianum, $P$. klotzschianum, $P$. mollicomum, $P$. rivinoides e $P$. tuberculatum.
\end{abstract}

Palavras-chave: flora, Floresta Ombrófila Densa, Mata Atlântica, taxonomia.

\begin{abstract}
The genus Piper has a pantropical distribution, containing about 2,000 species around the world. It is considered one of the ten major neotropical genera of Magnoliidae, and largest in Piperaceae. The study was conducted at

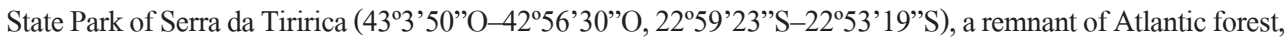
located at the border of the municipalities of Niterói and Maricá (RJ), with the goal of assessing the species belonging to the genus found in the area. Fertile plants were collected between 2011 to 2017 and sheets from the following herbaria were studied: FCAB, HB, R, RB, RBE, RBR, RFA, RFFP, as well as images from the virtual database SpeciesLink. Twelve species was found in the area: P. aduncum, P. amalago, P. amplum, P. anisum, $P$. arboreum var. arboreum, $P$. arboreum var. hirtelum, Piper corcovadensis var. corcovadensis, $P$. divaricatum, P. hoffmannseggianum, P. klotzschianum, P. mollicomum, $P$. rivinoides and P. tuberculatum.
\end{abstract}

Key words: flora, Dense Ombrophylous Forest, Atlantic Forest, taxonomy.

\section{Introdução}

Piperaceae possui distribuição pantropical e inclui cerca de 3.700 espécies distribuídas em cinco gêneros (Jaramillo et al. 2004; Wanke et al. 2006). No Brasil são encontradas 463 espécies, concentradas principalmente na Amazônia e Mata Atlântica, distribuídas nos gêneros Piper L., Peperomia Ruiz \& Pav. e Manekia Trel. (Flora do
Brasil 2020 em construção). A família está inserida no clado das Magnoliídeas, ordem Piperales, junto com Aristolochiaceae e Saururaceae (APG IV 2016).

São ervas eretas, epífitas, terrestre, subarbustos, arbustos, arvoretas ou trepadeiras; geralmente aromáticas e dotadas de glândulas translúcidas, com tipo de indumento variado.

Veja material suplementar em <https://doi.org/10.6084/m9.figshare.12421127.v1>

\footnotetext{
${ }^{1}$ Universidade Federal do Rio de Janeiro (UFRJ), Museu Nacional, Quinta da Boa Vista s/n, São Cristóvão, 20940-040, Rio de Janeiro, RJ, Brasil.

${ }^{2}$ Universidade do Estado do Rio de Janeiro, Faculdade de Formação de Professores (UERJ), Depto. Ciências (DCIEN), Grupo de Estudos Interdisciplinares do Ambiente (GEIA), R. Dr. Francisco Portela 1470, Patronato, 24435-005, São Gonçalo, RJ, Brasil.

${ }^{3}$ Instituto de Pesquisas Jardim Botânico do Rio de Janeiro (JBRJ), R. Pacheco Leão 915, Jardim Botânico, 22460-030, Rio de Janeiro, RJ, Brasil.

${ }^{4}$ ORCID: <https://orcid.org/0000-0001-7823-4075>

${ }^{5}$ Autor para correspondência: georgeazevedo08@gmail.com
} 
Possuem folhas alternas, opostas ou verticiladas, simples e inteiras, de forma, consistência, tamanho e padrão de nervação diversos, geralmente com profilos; flores aclamídeas, andróginas ou unissexuadas, protegidas por uma bráctea floral de forma variada, dispostas esparsa ou densamente em espigas, racemos ou umbelas de espigas, axilares, terminais ou opostas às folhas, eretas ou curvas; estames geralmente 2-6, livres ou adnatos às paredes do ovário, anteras bitecas de deiscência rimosa; gineceu com 1-4 estigmas; ovário súpero, séssil, geralmente imerso na raque, mono, tri ou tetracarpelar, sincárpico, unilocular, uniovular. O fruto é uma drupa séssil ou pedicelada, de forma variada, endosperma escasso com perisperma, embrião mínimo (Yuncker 1972, 1973).

Piper L. é considerado um dos dez maiores gêneros neotropicais de Angiospermas e o maior em Piperaceae (Frodin 2004). Geralmente suas espécies habitam áreas sombreadas ou margens de rios, entretanto, podem ser comumente encontradas nas bordas de mata e no interior de clareiras, naturais ou abertas por ação antrópica (Greig 1993). Algumas espécies do gênero são consideradas plantas pioneiras e estão envolvidas no processo de regeneração e manutenção da diversidade de matas (Andrade et al. 2009).

No Brasil são registradas 291 espécies para o gênero, das quais 104 ocorrem no estado do Rio de Janeiro, destas, 14 são endêmicas. Distribui-se em todos os domínios fitogeográficos e no Rio de Janeiro é encontrado em Floresta Ombrófila Densa em todos os estratos altitudinais, restingas, vegetação sobre afloramentos rochosos e áreas antrópicas (Flora do Brasil 2020 em construção).

O Parque Estadual da Serra da Tiririca (PESET) foi criado pela Lei Estadual n ${ }^{\circ}$ 1901/91 de 29 de novembro de 1991, tendo seus "limites em estudo" estabelecidos pelo Decreto $\mathrm{n}^{\circ} 18.598$ de 19 de maio de 1993 para uma área de 2.400 ha (Pontes 1987; Barros \& Seoane 1999). Devido a sua importância para conservação da diversidade biológica, foi considerada em 1992 pela UNESCO como parte integrante da Reserva da Biosfera da Mata Atlântica. A Lei Estadual no 5079, de 03 de setembro de 2007, estipulou os limites definitivos com duas partes continentais (Serra da Tiririca e Morro das Andorinhas) e uma marinha (Enseada do Bananal), numa área de 2.077 ha. Esses limites foram ampliados pelo Decreto-Lei $n^{\circ} 41.266$ de 16 de abril de 2008, abrangendo uma área de 186 ha no entorno da Laguna de Itaipu, resultando na inclusão de três sítios arqueológicos: Duna Grande,
Duna Pequena e Sambaqui Camboinhas (Barros \& Pimentel 2010). Em 2012 o PESET passou por mais um processo de ampliação, onde cerca de 90\% da Reserva Ecológica Darcy Ribeiro, as Ilhas do Pai, Mãe e Menina (somente parte emersa) e o Morro da Peça foram inseridos ao PESET. Sendo assim, o PESET atualmente totaliza uma área de $3.493 \mathrm{ha}$, com perímetro de 152,55 km (INEA 2015). A ocupação humana remonta a pré-história, quando grupos de caçadores-coletores nômades utilizavam a região para obtenção de recursos alimentícios acerca de oito mil anos atrás. A partir do século XVIII até meados do XX, as atividades agrícolas (plantações de cana-de-açúcar, café, banana, culturas de subsistência) implantadas pelos colonizadores europeus, a produção de carvão vegetal, além da mineração de saibro e argila, alteraram significativamente a vegetação original. Atualmente essas transformações vêm sendo intensificadas devido à especulação imobiliária que ocorre na Região Oceânica do município de Niterói e em Itaipuaçu no município de Maricá (Barros \& Pimentel 2010).

No estado do Rio de Janeiro foram realizados os estudos para o município do Rio de Janeiro (Ichaso et al. 1977); Reserva Ecológica de Macaé de Cima (Guimarães 1994a); Serra dos Órgãos (Guimarães 1994b); Área de Proteção Ambiental de Cairuçu (Guimarães \& Giordano 1997); Reserva Biológica de Poço das Antas (Guimarães \& Monteiro 2006); Parque Nacional do Itatiaia (Monteiro \& Guimarães 2009), no entanto, nenhum estudo em Piper foi realizado no Parque Estadual da Serra da Tiririca, uma área pouco conhecida no contexto taxonômico. Somado a este fato, o PESET ocupa $18,6 \%$ do território de Niterói sendo a maior unidade de conservação do município e 2,35\% da área total de Maricá, mostrando assim, a importância deste Parque para a região (INEA 2015).

No intuito de ampliar o conhecimento da diversidade para a família, e, consequentemente sanar a lacuna de conhecimento para o gênero nesta região é apresentado o tratamento taxonômico para Piper no Parque Estadual da Serra da Tiririca.

\section{Material e Métodos}

O Parque Estadual da Serra da Tiririca (Fig. 1a) está localizado entre os municípios de Niterói e Maricá, no estado do Rio de Janeiro (433'50'O-

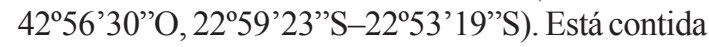
no bioma Mata Atlântica, sendo sua vegetação classificada como Floresta Ombrófila Densa (MMA 

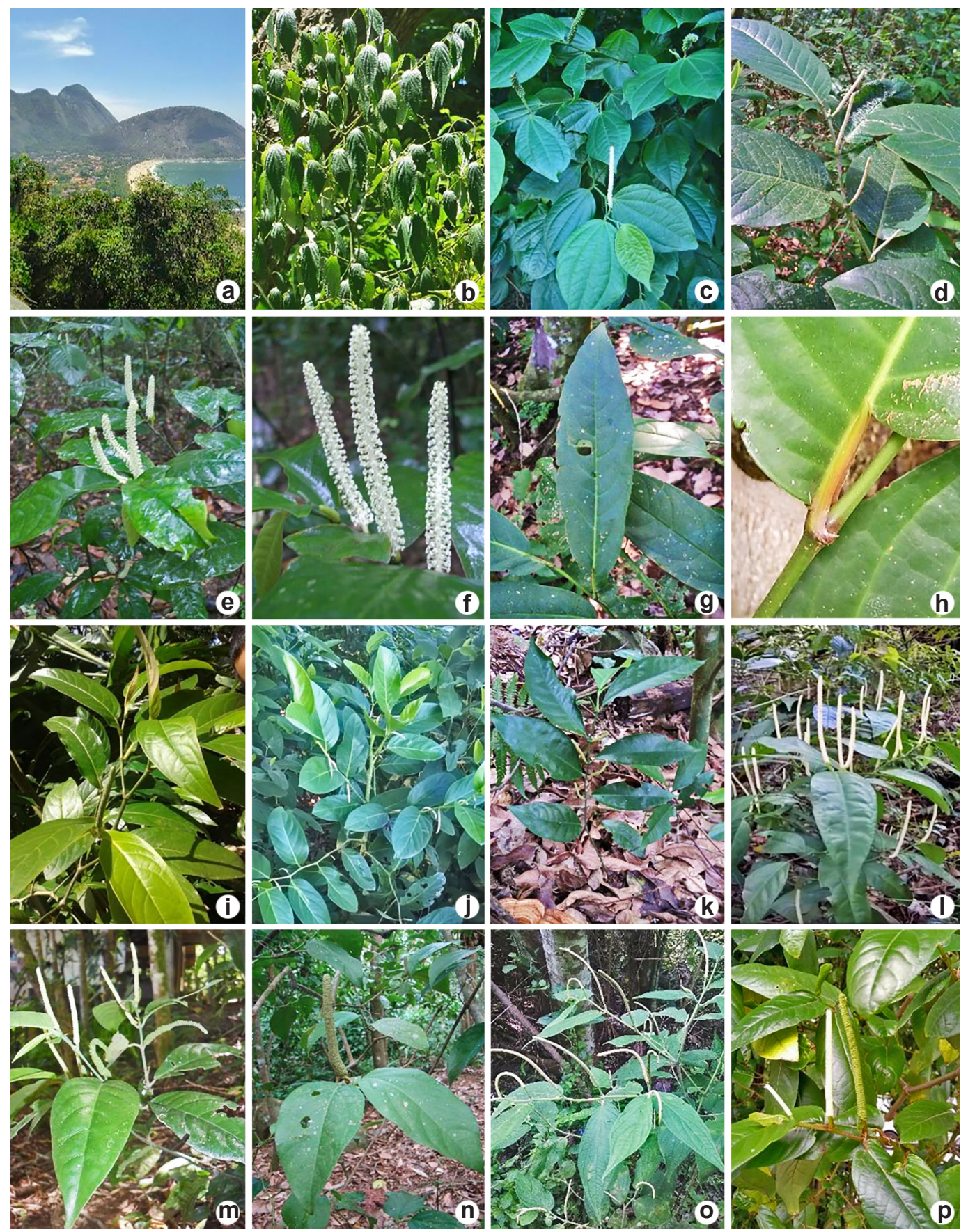

Figura 1 - Vista parcial do Parque Estadual da Serra da Tiririca, Rio de Janeiro, Brasil, e espécies de Piper inventariadas - a. vista do Alto Mourão e Costão de Itacoatiara; b. hábito de $P$. aduncum; c. hábito de $P$. amalago; d. hábito de $P$. amplum; e. hábito de $P$. anisum; f. inflorescência de $P$. anisum; g. lâmina foliar de $P$. arboreum var. arboreum; h. base da lâmina foliar de $P$. arboreum var. arboreum; i. hábito de $P$. arboreum var. hirtelum; j. hábito de $P$. divaricatum; k. hábito jovem de $P$. hoffmannseggianum; 1 . hábito adulto de $P$. hoffmannseggianum; $\mathrm{m}$. hábito de $P$. klotzschianum; $\mathrm{n}$. hábito de $P$. mollicomum; o. hábito de $P$. rivinoides; p. hábito de $P$. tuberculatum.

Figure 1 - Partial overview of State Park of Serra da Tiririca, Rio de Janeiro, Brazil and species of Piper assessed - a. view of Alto Mourão and Costão de Itacoatiara; $\mathrm{b}$. habit of $P$. aduncum; $\mathrm{c}$. habit of $P$. amalago; d. habit of $P$. amplum; $\mathrm{e}$. habit of $P$. anisum; $\mathrm{f}$. inflorescence of $P$. anisum; g. leaf blade of $P$. arboreum var. arboreum; h. base of the leaf blade of $P$. arboreum var. arboreum; i. habit of $P$. arboreum var. hirtelum; $\mathrm{j}$. habit of $P$. divaricatum; $\mathrm{k}$. young habit of $P$. hoffmannseggianum; 1 . adult habit of $P$. hoffmannseggianum; $\mathrm{m}$. habit of $P$. klotzschianum; $\mathrm{n}$. habit of $P$. mollicomum; o. habit of $P$. rivinoides; $\mathrm{p}$. habit $P$. tuberculatum. 
2015), com extensas áreas cobertas pela formação Submontana em vários estágios sucessionais (Barros et al. 2009). Segundo a classificação de Köppen, o clima é do tipo $A w$, variando entre quente e úmido, com estação chuvosa no verão e seca no inverno (Kottek et al. 2006). Apresenta rochas précambrianas, com cerca de 600 milhões de anos, compreendendo as unidades geológicas gnaisse facoidal e Cassorotiba (Penha 1999). Os solos são do tipo Argissolo Vermelho-Amarelo, Cambissolo Háplico, Neossolo Litólico (INEA 2015), sendo a classificação adaptada de acordo com Embrapa (2006).

Foram realizadas coletas aleatórias de plantas férteis entre os meses de setembro de 2011 a abril de 2017, para complementar as coletas já existentes depositadas nos herbários fluminenses. As amostras foram herborizadas segundo técnicas usuais utilizadas em inventários florísticos (Guedes-Bruni et al. 2002) e o material testemunho incorporado aos herbários RFFP e RB (acrônimos conforme Thiers, continuamente atualizado). As espécies coletadas foram identificadas através de bibliografia especializada, dentre essas se destacam os trabalhos de Yuncker (1972, 1973), além de comparações nos herbários nacionais e internacionais (on line). $\mathrm{O}$ estudo taxonômico abrangeu pesquisa bibliográfica sobre os táxons, além de consultas aos herbários HB, R, RB, RBR, RBE, RFA, RFFP e FCAB, (acrônimos conforme Thiers, continuamente atualizado) e do banco de dados virtual SpeciesLink (CRIA 2018). As descrições foram realizadas com o auxílio de microscópio estereoscópico. A lista dos materiais examinados foi selecionada, no entanto, todos os espécimes analisados são apresentados no índice de coletores e na Tabela S1, disponibilizada no material suplementar $<$ https://doi.org/10.6084/ m9.figshare.12421127.v1>. A fenologia foi estabelecida com base nos materiais coletados na região. Para a elaboração da distribuição geográfica seguiu-se obras de revisão do gênero, $\mathrm{W}^{3}$ Tropicos (Tropicos 2018) e Flora do Brasil 2020 (em construção). As espécies são apresentadas em ordem alfabética, sendo oferecidas descrições, chave para identificação das mesmas, comentários e distribuição geográfica.

\section{Resultados e Discussão}

Foram registrados 12 táxons de Piper no Parque Estadual da Serra da Tiririca, habitando áreas secas e úmidas, interior e borda de mata, beiras de estradas e outras áreas ensolaradas. Destaca-se Piper klotzschianum que é registrado pela primeira vez segundo levantamento de herbários no Parque Estadual da Serra da Tiririca, sendo considerado um táxon raro no Rio de Janeiro.

Piper L. Sp. pl. - 1: 28.1753.

Subarbustos, arbustos ou arvoretas, de caules intumescidos; ramos eretos com nós proeminentes. Folhas alternas, membranáceas, papiráceas ou cartáceas quando in natura; bainha basal ou prolongando-se até a lâmina, podendo ser alada; lâminas de forma, consistência e tamanhos variáveis, providas ou não de glândulas, margens inteiras; profilos persistentes ou caducos; padrão de nervação acródromo basal, broquidódromo ou eucampidódromo. Inflorescências em espigas ou racemos, opostas às folhas ou em umbelas axilares, eretas, curvas ou flexuosas; brácteas presentes ou ausentes no pedúnculo; flores bissexuais, dispostas em raque glabra ou fimbriada, protegidas por bráctea floral de diversas formas, pediceladas, variando de glabra a pilosa; ovário elíptico, obovoide, ovoide, tri ou tetragonal; estames 3-6. Fruto drupa, globosa, ovoide, obovoide, trigonal, oblonga ou tetragonal, glabra ou pilosa, pericarpo delgado, estigmas 3-4 com estiletes curto ou séssil.

Espécie tipo: Piper nigrum L.

\section{Chave de identificação das espécies de Piper ocorrentes na Serra da Tiririca}

1. Folhas com padrão de nervação acródromo basal ...................................................... 2. Piper amalago

1'. Folhas com padrão de nervação broquidódromo, eucamptódromo .......................................................2

2. Nervuras secundárias surgindo da base até a porção mediana, nunca até o ápice........................... 3

3. Face abaxial da lâmina foliar vilosa, tricomas sedosos ao tato........... 10. Piper mollicomum

3'. Face abaxial da lâmina foliar híspido-tomentosa, tricomas ásperos ao tato

1. Piper aduncum

2'. Nervuras secundárias surgindo da base até o ápice ................................................................. 4

4. Frutos trigonais............................................................................... 11. Piper rivinoides

4'. Frutos globosos, ovoides, obovoides, oblongos ou tetragonais ............................................ 5 


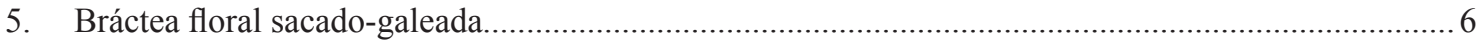

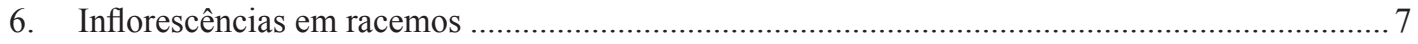

7. Lâmina foliar densamente pilosa ao longo da nervura primária na face abaxial

7'. Lâmina foliar glabra ao longo da nervura primária na face abaxial

4. Piper anisum

6. Piper corcovadensis

6'. Inflorescências em espigas ......

8

8. Folhas glabras em ambas as faces, exceto pela presença de tricomas hirtelos na nervura submarginal da face abaxial; raque pubescente .............................. 9. Piper klotzschianum

8'. Folhas glabras inclusive na nervura submarginal da face abaxial; raque glabra a levemente fimbriada ..... 8. Piper hoffmannseggianum

5'. Bráctea floral cuculado-crescente, arredondada ou triangular, peltada, franjada 9

9. Base da lâmina foliar assimétrica, um lado 5-20 mm mais curto em relação ao outro lado ....... 10

10. Ramos e pecíolos verruculosos .......................................................12. P. tuberculatum

10'. Ramos e pecíolos não verruculosos ....................................................... Piper arboreum

9'. Base da lâmina foliar simétrica ou subassimétrica, um lado 2-3 mm mais curto em relação ao outro lado.

7. Piper divaricatum

11. Nervuras secundárias 5-8; fruto com ápice convexo. 3. Piper amplum

11'. Nervuras secundárias 12-14; fruto com ápice depresso . 
abaxial; profilo persistente; nervuras secundárias partindo da base da lâmina, 5-7, direcionadas ao ápice; padrão de nervação acródromo basal. Espiga 3-7 $\times 0,2-0,5 \mathrm{~cm}$, ereta, raque glabra; pedúnculo $0,5-1,5 \mathrm{~cm}$ compr., glabro ou pubescente; bráctea floral subtriangular, peltada, franjada, glabra; flores sésseis; estames 5-6; ovário com estilete curto ou séssil, 3 estigmas. Fruto $1-2 \times 1-1,5 \mathrm{~mm}$, ovoide, anguloso, papiloso, ápice agudo, glabro.

Material selecionado: divisa dos municípios de Maricá e Niterói, Alto Mourão, trilha via Itaipuaçu, 7.V.2012, fl., G.A. de Queiroz et al. 35 (RB, RFFP). Niterói, Morro do Cordovil, Vale das Borboletas, trilha da Jararaca, 26.III.2013, fr., G.A. de Queiroz et al. 106 (RB, RFFP); na confluência da Av. Central com a Rua Itália, 23.III.2017, fl. e fr., D.N.S. Machado et al. 2031 (RB, RFFP); Morrote do Vale dos Colibris, 10.III.2012, fr., G.A. de Queiroz et al. 28 (RB, RFFP); Morro do Telégrafo, Rua 31, quadra 45, 5.X.2011, fl., G.A. de Queiroz et al. 04 (RB, RFFP); Córrego dos Colibris, 5.IV.2013, fl. e fr., G.A. de Queiroz et al. 111 (RB, RFFP). Maricá, Morro da Penha, acesso pela Rua Domingos Barbosa, 3.V.2013, fr., G.A. de Queiroz, et al. 117 (RFFP); Morro da Serrinha, antigo túnel ferroviário, 28.V.2014, fl. e fr., G.A. de Queiroz et al. 145 (RB, RFFP); Morro do Telégrafo, Sítio do Céu, 16.X.2002, fr. V.C. de Matos et al. 18 (RB, RFFP).

Piper amalago é um arbusto ciófilo a heliófilo, frequentemente encontrado no Parque em borda ou interior da mata. Facilmente reconhecido devido às suas folhas com padrão de nervação acródromo basal, além da inflorescência ereta. Ainda in natura, após maceração das folhas, libera odor característico. Ilustração em Steyermark (1984), Guimarães \& Valente (2001).

Espécie encontrada na Argentina, Belize, Bolívia, Brasil, Caribe, Colômbia, Costa Rica, El Salvador, Equador, Guatemala, Guiana francesa, Guiana, Honduras, México, Panamá, Peru, Suriname e Venezuela. No Brasil nas regiões Norte (Pará, Rondônia), Nordeste (Bahia, Ceará, Paraíba, Pernambuco), Centro-Oeste, Sudeste e Sul. (Yuncker 1950; Trelease \& Yuncker 1950; Steyermark 1984; W3 Tropicos (Tropicos 2018); Flora do Brasil 2020 (em construção).

Coletado florescendo nos meses de maio, junho, setembro, outubro, novembro e dezembro. Frutificando nos meses de janeiro, fevereiro, março, abril, maio, junho, agosto, outubro, novembro de dezembro.

3. Piper amplum Kunth, Linnaea 13: 618. 1839.

Fig. 1d

Arbusto 1-2,5 m alt.; ramos 5-10 mm diâm., cilíndricos, sulcados, glabros. Folhas com pecíolo 1,5-2,5 cm compr., estriado, canaliculado, glabro; bainha basal; lâmina $18,5-24 \times 7,5-12,5 \mathrm{~cm}$, discolor verde, papirácea, oblongo-lanceolada, elíptica, ovado-elíptica, subtranslúcida, glândulas esparsas, base simétrica ou subassimétrica, obtusa, aguda, subcordada, um lado $2-3 \mathrm{~mm}$ mais curto em relação ao outro, ápice agudo, glabra em ambas as faces, às vezes, com leve pubescência na face abaxial; profilo caduco; nervuras secundárias partindo da nervura principal $12-14$ surgindo da base até o ápice, direcionadas às margens; padrão de nervação broquidódromo. Espiga de 5-9,5 $\times 0,2-0,4 \mathrm{~cm}$, ereta, raque glabra; pedúnculo $0,7-1 \mathrm{~cm}$ compr., glabro; bráctea floral cuculadocrescente, glabra; flores sésseis; estames 4; ovário com estilete curto ou séssil; 3 estigmas. Fruto 1,6-2 $\times 1-1,2 \mathrm{~mm}$, obovoide, oblongo, subanguloso, ápice depresso, glabro.

Material selecionado: divisa dos municípios de Maricá e Niterói, Alto Mourão, trilha para o Alto Mourão, 7.V.2012, fr., G.A. de Queiroz et al. 38 (RB, RFFP). Niterói, Córrego dos Colibris, 10.III.2012, fr., G.A. de Queiroz et al. 30 (RB, RFFP); Morro do Telégrafo, Morrote do Vale dos Colibris, 10.III.2012, fr., G.A. de Queiroz et al. 29 (RB, RFFP); Morro do Cordovil, Vale das Borboletas, trilha da Jararaca, 26.III.2013, fr., G.A. de Queiroz et al. 107 (RB, RFFP); Morro do Telégrafo, Sítio Três Nascentes, 8.X.2000, f1. e fr., W.B. Carvalho et al. 207 (RB, RFFP).

Piper amplum é um arbusto ciófilo, muito comum na área em estudo, reconhecido no local pelas folhas vistosas, elípticas, brilhantes na face adaxial, com pecíolo estriado, canaliculado e inflorescências eretas. Ilustração em Guimarães \& Valente (2001).

Ocorre na Guiana Francesa e no Brasil nas regiões Norte (Acre, Rondônia), Nordeste (Bahia, Pernambuco), Centro-oeste (Distrito Federal, Goiás, Mato Grosso), Sudeste e Sul (Funk et al. 2007; $\mathrm{W}^{3}$ Tropicos (Tropicos 2018); Flora do Brasil 2020 (em construção).

Coletado florescendo nos meses de fevereiro a maio e de julho a outubro. Frutificando de fevereiro a setembro.

4. Piper anisum (Spreng.) Angely, Flora Descritiva do Paraná 2: 387. $1978 . \quad$ Fig. 1e-f

Subarbusto ou arbusto $1-1,7 \mathrm{~m}$ alt.; ramos 2-3 mm diâm., cilíndrico, estriados, esparsamente pubescentes. Folhas com pecíolo 0,2-0,4 cm compr., cilíndrico, glabro; bainha basal; lâmina $6-13 \times 1,5-5 \mathrm{~cm}$, discolor verde, membranácea, suboblongo-elíptica, subovadoelíptica, translúcida, eglandulosa, base simétrica ou assimétrica, um lado $0,8-1 \mathrm{~mm}$ mais curto em 
relação ao outro, ápice acuminado; face adaxial glabra, face abaxial densamente pilosa ao longo da nervura primária; profilo caduco; nervura secundárias partindo da nervura principal 6-8 surgindo desde a base até o ápice, direcionadas as margens; padrão de nervação eucamptódromo. Racemo 6,5-7 × 0,5-0,8 cm, ereto, raque hirtela; pedúnculo 0,5-1,3 cm compr., hirtelo; bráctea floral sacado-galeada, glabra, hirtela; flores pediceladas; pedicelo 2,5-2,8 mm compr.; estames 4; ovário com estilete curto ou séssil; 4 estigmas. Fruto $1,8-2 \times 0,8-1 \mathrm{~mm}$, globoso ou ovoide, tetragonal, fortemente sulcado, papiloso, ápice apiculado, hirto.

Material examinado: Morro do Telégrafo, Sítio Três Nascentes, 8.X.2000, fr., W.B. de Carvalho et al. 230 (RB).

Piper anisum é um arbusto ciófilo, crescendo em locais úmidos no interior da mata. Pouco abundante no Parque Estadual da Serra da Tiririca, sendo observado apenas no Morro do Telégrafo, entretanto, fácil de ser reconhecido devido aos seus frutos pedicelados, além da lâmina suboblongo-elíptica, subovado-elíptica com nervuras secundárias surgindo da base até o ápice. Ilustração em Miquel (1852).

Endêmico do Brasil ocorrendo nas regiões Nordeste (Bahia, Pernambuco), CentroOeste (Goiás) e Sudeste (Callejas 1986; Flora do Brasil 2020 (em construção)).

Coletado frutificando no mês de outubro.

5. Piper arboreum Aubl., Hist. pl. Guiane 1: 23. 1775.

Arbusto ou arvoreta, 1-4 m alt.; ramos 4-8 mm diâm., cilíndrico, sulcados, glabros. Folhas com pecíolo 3-5 cm compr., estriado, canaliculado-alado; bainha longa percorrendo toda a extensão do pecíolo; lâmina 9,5-19 × 2-5,5 $\mathrm{cm}$, discolor verde, membranácea ou papirácea, oblongo-elíptica, ovada, oblongo-lanceolada, translúcida, eglandulosa, base assimétrica, aguda 10-20 mm mais curto em relação ao outro, ápice agudo-acuminado, glabra em ambas as faces ou com tricomas na face abaxial principalmente nas nervuras; profilo persistente; nervuras secundárias partindo da nervura principal 10-12 surgindo da base até o ápice; padrão de nervação broquidódromo a eucamptódromo. Espiga 7-12 × 0,3-0,5 cm, ereta, raque glabra; pedúnculo $0,5-2 \mathrm{~cm}$ compr., glabro; bráctea floral triangular, peltada, franjada; flores sésseis, estames 4; ovário com estilete curto ou séssil, 3 estigmas. Fruto 0,8-1 × 1,2-1,5 mm, oblongo, lateralmente achatado, ápice obtuso ou truncado, glabro.

5.1. Piper arboreum Aubl. var. arboreum, Hist. pl. Guiane 1: 23. 1775 . Fig. 1g-h Arbusto ou arvoreta 1-4 m de alt., lâmina foliar e nervuras glabras na face abaxial.

Material selecionado: Maricá, Morro da Serrinha, antigo túnel ferroviário, 28.IV.2014, fl. e fr., G.A. de Queiroz et al. 143 (RB, RFFP). Niterói, Córrego dos Colibris, 28.XI.1997, fr., R. de C.C. Silva et al. 45 (RB, RFFP); Morro do Cordovil, 5.VI.2015, fr., D.N.S. Machado et al. 620 (RFFP); Morro das Orações, 17.VII.2016, fl., G.A. de Queiroz \& D.N.S. Machado 383 (RB); Morro do Telégrafo, Sítio Grotão de Manoel Bonfim, 8.IV.2005, fl., A.A.M. de Barros \& N. Coqueiro 2468 (RFFP).

Piper arboreum var. arboreum é um arbusto ciófilo a heliófilo, onde se destaca pelas folhas vistosas, brilhantes, geralmente verde-vinosa. É facilmente identificado pelas folhas de formato oblongo-elíptica, ovada, oblongo-lanceolada com base acentuadamente assimétrica, pecíolo que se projeta sobre a base da lâmina na face adaxial e inflorescências eretas. Ilustração em Tebbs (1989).

Ocorre em Belize, Bolívia, Brasil, Colômbia, Costa Rica, Cuba, Equador, Guatemala, Guiana Francesa, Guiana, Honduras, Jamaica, México, Nicarágua, Panamá, Paraguai, Peru, Porto Rico, Suriname, Trinidad e Venezuela. No Brasil nas regiões Norte, Nordeste (Alagoas, Bahia, Ceará, Paraíba, Pernambuco, Sergipe), Centro-Oeste, Sudeste e Sul (Trelease \& Yuncker 1950; Tebbs 1989; Steyermark 1984; $\mathrm{W}^{3}$ Tropicos (Tropicos 2018); Flora do Brasil 2020 (em construção).

Coletado florescendo nos meses de janeiro, abril a julho, outubro e frutificando nos meses de março a junho, agosto, outubro e novembro.

5.2. Piper arboreum var. hirtellum Yunck., Ann. Missouri Bot. Gard. 37:64. 1950. Fig. 1i

Arbusto ou arvoreta 1-4 m alt., lâmina foliar e nervuras hirtelas na face abaxial.

Material examinado: Niterói, Morro do Cordovil, Vale das Borboletas, Trilha da Jararaca, 26.III.2013, fr., G.A. de Queiroz et al. 105 (RB, RFFP); 21.III.2013, fl. e fr., D.N.S. Machado et al. 411 (RFFP); Morro do Telégrafo, Córrego dos Colibris, 1.V.2014, fr., G.A. de Queiroz et al. 154 (RB, RFFP); Morro do Cordovil, 5.VI.2015, fr., D.N.S. Machado et al. 621 (RFFP).

Piper arboreum var. hirtellum foi registrado pela primeira vez para o Parque Estadual da Serra da Tiririca, sendo encontrado no interior da mata compondo o sub-bosque na Floresta Ombrófila Densa Submontana no Morro do Cordovil e no 
Córrego dos Colibris. Diferencia-se da variedade típica por apresentar a face abaxial providas de tricomas. Ilustração em Queiroz (2017).

Ocorre na Guiana, Panamá, Suriname e Venezuela. No Brasil nas regiões Norte (Acre, Amazonas, Rondônia, Roraima, Tocantins), Nordeste (Bahia, Ceará, Paraíba, Pernambuco), Centro-Oeste (Distrito Federal, Goiás, Mato Grosso do Sul, Mato Grosso), Sudeste (Espírito Santo, Minas Gerais, Rio de Janeiro, São Paulo) e Sul (Paraná, Santa Catarina) (Yuncker 1950; Trelease \& Yuncker 1950; Steyermark 1984; W ${ }^{3}$ Tropicos (Tropicos 2018); Flora do Brasil 2020 (em construção).

Coletado florescendo em fevereiro, março, maio, junho e frutificando nos meses de fevereiro, março, maio e junho.

\section{Piper corcovadensis (Miq.) C. DC. var. corcovadensis Prodr. 16(1): 255. 1869.}

Arbusto ca. $2 \mathrm{~m}$ de alt.; ramos $2-3 \mathrm{~mm}$ de diâm., estriados, cilíndricos, lisos, glabros.

Folhas com pecíolo 0,3-1 cm de compr., cilíndrico, estriado, sulcado, glabro; bainha basal; lâmina 12,1-16,9 × 4,4-6,2 cm, discolor, papirácea, lanceolada, oblongo-lanceolada, elíptico-lanceolada, não traslucido-glandulosa, base simétrica ou subsimétrica, obtuso-cordada, aguda, um lado diferindo do outro 1-1,5 mm em relação ao outro lado, ápice agudo ou acuminado, glabra em ambas as faces; profilo caduco; nervuras secundárias partindo da nervura principal 8-9 inseridas desde a base até o ápice da lâmina, direcionadas as margens; padrão de nervação eucamptódromo a broquidódromo. Racemo 3-3,6 × 0,5-0,6 cm, ereto, raque glabra ou sub-hirta; pedúnculo $0,4-0,7 \mathrm{~cm}$, glabro; bráctea floral sacado-galeada, hirta na margem; flores pediceladas; pedicelo $0,8-2,5 \mathrm{~mm}$ compr.; estames 4; ovário com estilete curto ou séssil, 4 estígmas. Fruto ca. $1,5-2 \times 1,5 \mathrm{~mm}$, oblongoovóide, oblongo-tetragonal, sulcado, ápice agudoapiculado, glabro.

Material examinado: Reserva Ecológica Darcy Ribeiro, Serra Grande, 28.VI.2004, fl., A.A.M. de Barros et al. 2197 (RB, RFFP); Serra do Malheiro, Sítio Pomar, 3.VI.2005, fl. e fr., N. Coqueiro et al. 119 (RFFP).

Piper corcovadensis var. corcovadensis é caracterizado pelas flores, com pedicelos além de $0,7 \mathrm{~mm}$, lâmina foliar não translúcido glandulosa, glabra. Ilustração em Guimarães \& Monteiro (2006).

Endêmico do Brasil nas regiões Norte (Pará),
Nordeste (Bahia, Ceará, Paraíba, Pernambuco), Centro-Oeste (Goiás), Sudeste (Espírito Santo, Minas Gerais, Rio de Janeiro, São Paulo) e Sul (Paraná, Rio Grande do Sul, Santa Catarina) (Callejas 1986; $\mathrm{W}^{3}$ Tropicos (Tropicos 2018); Flora do Brasil 2020 (em construção).

Coletado florescendo e frutificando no mês de junho.

7. Piper divaricatum G. Mey., Prim. Fl. Esseq. 15, fig. 86. 1818.

Fig. $1 \mathrm{j}$

Arbusto 2-4 m de alt.; ramos 2-4 mm de diâm., sulcado, cilíndrico, lisos, glabros. Folhas com pecíolo 0,4-1,2 cm compr., sulcado, cilíndrico, glabro; bainha basal; lâmina 9,5-15,5 $\times 3,8-6,5 \mathrm{~cm}$, discolor verde, papirácea ou membranácea, oblongo-elíptica, lanceolada, translucida, glandulosa, base assimétrica, um lado diferindo do outro $2-3 \mathrm{~mm}$ em relação ao outro lado, ápice agudo ou acuminado, glabra em ambas as faces; profilo caduco; nervuras secundárias partindo da nervura principal 5-8, inseridas desde a base até o terço superior, ou acima, atingindo o ápice da lâmina, direcionadas ao ápice; padrão de nervação eucamptódromo. Espiga 4,5-7,7 × 0,4-1 cm, ereta, pêndula ou curvada, raque glabra; pedúnculo $0,5-0,8 \mathrm{~cm}$ compr., glabro; bráctea floral arredondada, triangular, peltada, franjada, pilosa; flores sésseis; estames 4; ovário com estilete séssil, 3 estígmas. Fruto ca. $2-3 \times 1,5 \mathrm{~mm}$, oblongo, anguloso, ápice convexo, glabro.

Material examinado: Niterói, Reserva Ecológica Darcy Ribeiro, Serra do Cantagalo, Sítio do Acácio, 17.III.2012, fr., D.N.S. Machado et al. 34 (RFFP).

Piper divaricatum é caracterizado pelas lâminas oblongo-elípticas, lanceoladas, glabras, glandulosas de inflorescências eretas, pêndulas ou curvadas. Ilustração em Tebbs (1990); Guimarães \& Monteiro (2006).

Ocorre na Bolívia, Brasil, Equador, Guiana, Guiana Francesa, Suriname, Venezuela. No Brasil nas regiões Norte (Acre, Amazonas, Amapá, Pará, Rondônia, Roraima), Nordeste (Alagoas, Bahia, Ceará, Maranhão, Pernambuco, Sergipe), Centrooeste (Distrito Federal, Goiás, Mato Grosso do Sul, Mato Grosso) e Sudeste (Espírito Santo, Minas Gerais, Rio de Janeiro, São Paulo) (Tebbs 1990; Steyermark 1984; W3 ${ }^{3}$ Tropicos (Tropicos 2018); Flora do Brasil 2020 (em construção).

Coletado frutificando no mês de março.

8. Piper hoffmannseggianum Roem. \& Schult., 
Mant. 1: 242. 1822.

Fig. 1k-1

Subarbusto ou arbusto, 1-3 m alt.; ramos 0,8-2 cm diâm., cilíndricos estriados, lisos, glabros. Folhas com pecíolo $0,5-1 \mathrm{~cm}$ compr., canaliculado, glabro; bainha basal; lâmina $8-12,5$ $\times 3-4 \mathrm{~cm}$, discolor verde, cartácea a papirácea, oblongo-lanceolada, oblongo-elíptica, translúcida, eglandulosa, base simétrica ou subsimétrica, obtusa ou subaguda, um lado $1-1,5 \mathrm{~mm}$ mais curto em relação ao outro lado, ápice agudo, glabra em ambas as faces, inclusive na nervura submarginal da face abaxial; profilo caduco; nervuras secundárias partindo da nervura principal 8-12 surgindo da base até o ápice, inseridas ao longo da nervura mediana direcionadas às margens; padrão de nervação broquidódromo. Espiga 4,5-6,5 × 0,2-0,3 cm, ereta, podendo ser curva, raque glabra a levemente fimbriada; pedúnculo $0,8-1 \mathrm{~cm}$ compr., glabro; bráctea floral sacado-galeada, glabra, pedicelo, às vezes, hirsuto; flores sésseis; estames 4; ovário com estilete curto ou séssil; 4 estigmas. Fruto 1,8-2 $\times$ 0,6-0,8 mm, oblongo, tetragonal, ápice convexo, liso ou papiloso.

Material selecionado: Niterói, Morro do Cordovil, Vale das Borboletas, Trilha da Jararaca, 26.III.2013, fr., G.A. de Queiroz et al. 109 (RB, RFFP); Morro do Telégrafo, Trilha da Barreira, 29.X.2011, fl., G.A. de Queiroz et al. 07 (RB, RFFP); Morro do Telégrafo, 21.V.2015, fl. e fr., D.N.S. Machado et al. 619 (RFFP); Morrote do Vale dos Colibris, 10.III.2012, fr., G.A. de Queiroz et al. 31 (RB, RFFP); Córrego dos Colibris, 7.VI.2013, fr., G.A. de Queiroz et al. 118 (RFFP); Morro das Orações, 17.VII.2006, fl. e fr., G.A. de Queiroz \& D.N.S. Machado 382 (RB, RFFP); Estrada Vai e Vem, 5.VI.2015, fr., D.N.S. Machado et al. 632 (RFFP); Sítio Três Nascentes, 8.X.2000, fl., W.B. de Carvalho et al. 237 (RB, RFFP); Trilha da Cumeeira, 14.VI.2006, fl., A.A.M. de Barros et al. 2662 (RB, RFFP).

Piper hoffmannseggianum é um arbusto ciófilo ou semi-heliófilo bastante comum no estado do Rio de Janeiro distribuindo-se na Serra da Tiririca nos Morros do Telégrafo e Cordovil. Esta espécie é morfologicamente semelhante à $P$. klotzschianum, dele diferindo pela lâmina glabra em ambas as faces, inclusive na nervura submarginal da face abaxial e raque glabra a levemente fimbriada. Ilustração em Ichaso et al. (1977).

Endêmico do Brasil, ocorrendo nas regiões Norte (Pará), Nordeste (Bahia), CentroOeste (Distrito Federal), Sudeste (Espírito Santo, Minas Gerais, Rio de Janeiro, São Paulo) e Sul (Paraná) (Callejas 1986; Flora do Brasil 2020 (em construção)).

Coletado florescendo nos meses de fevereiro, março, maio, junho, agosto, setembro e outubro. Frutificando nos meses de janeiro a junho, setembro, outubro e dezembro.

9. Piper klotzschianum (Kunth) C. DC., Prodr. 16(1): 257. 1869.

Fig. $1 \mathrm{~m}$

Subarbusto ou arbusto, 1-2 m alt.; ramos 4-5 mm diâm., cilíndricos, estriados, lisos glabros. Folhas com pecíolo $0,5-1 \mathrm{~cm}$ compr., estriado, glabro; bainha basal; lâmina 12,5-10,5 × 4,5-5,9 $\mathrm{cm}$, discolor verde, cartácea a membranácea, oblongo-lanceolada, oblongo-elíptica, translúcida, eglandulosa, base aguda, obtusa, arredondadocordada, subassimétrica um lado $1 \mathrm{~mm}$ mais curto em relação ao outro lado, ápice agudo, glabra em ambas as faces, exceto pela presença de tricomas hirtelos na nervura submarginal da face abaxial; profilo persistente; nervuras secundárias partindo da nervura principal 9-11 surgindo da base até o ápice; padrão de nervação broquidódromo. Espiga $4,2-11,5 \times 0,2-0,3 \mathrm{~cm}$, ereta ou curva, raque pubescente; pedúnculo de $0,5-0,8 \mathrm{~cm}$ compr., glabro; bráctea floral sacado-galeada, glabra; flores sésseis; estames 4; ovário com estilete curto ou séssil; 4 estigmas. Fruto 1,8-2,5 × 1,5-2 mm, ovoide, tetragonal, ápice subapiculado, glabro.

Material examinado: Niterói, Morro do Telégrafo, Rua 31, quadra 45, lote 2, 5.X.2011, fl., G.A. de Queiroz et al. 03 (RB, RFFP); 12.IV.2012, fl., A.A.M. de Barros 4554 (RB, RFFP); Vale do Jacaré, Reserva Ecológica Darcy Ribeiro, Serra do Cantagalo, Sítio do Acácio, 17.III.2012, fr., A.A.M. de Barros 4549 (RB, RFFP).

Material adicional examinando: BRASIL. RIO DE JANEIRO: Guapimirim, cerca de $3 \mathrm{~km}$ da estrada para Santo Aleixo, 27.XII.2000, fr., L.C. Giordano 2318 et al. (RB).

Piper klotzschianum segundo levantamento de herbários é registrado pela primeira vez no Parque Estadual da Serra da Tiririca, no Morro do Telégrafo, sendo considerado um táxon raro no Rio de Janeiro. É muito semelhante à $P$. hoffmannseggianum, não raro, encontrado e determinado como tal, entretanto é diferenciado pela presença de tricomas hirtelos na nervura submarginal da face abaxial e raque esparsamente pubescente. É reconhecida em campo pelo brilho peculiar das folhas glabras, bem como pelas inflorescências eretas, alvas e perfumadas. Ilustração em Guimarães et al. (2007).

Endêmica do Brasil, de ocorrência nas regiões Nordeste (Bahia), Centro-Oeste (Mato Grosso) e Sudeste (Espírito Santo, Minas Gerais, Rio de 
Janeiro) (Callejas 1986; Flora do Brasil 2020 (em construção)).

Coletado florescendo nos meses de abril e outubro.

10. Piper mollicomum Kunth, Linnaea 13: 648. 1839.

Fig. 1n

Arbusto, 1-3 m alt.; ramos 2-4 mm diâm., cilíndricos, sulcados, lisos, vilosos. Folhas com pecíolo $0,5-1 \mathrm{~cm}$ de compr., cilíndrico, viloso; bainha basal; lâmina $10-10,5 \times 4-5,5 \mathrm{~cm}$, discolor verde, membranácea, oblongo-elíptica, oblongo-lanceolada, translúcida, glandulosa, base assimétrica, o mais curto agudo ou obtuso, o mais longo arredondado ou cordulado, um lado diferindo do outro 2-4 mm em relação ao outro, ápice agudo ou acuminado, face adaxial escabra, face abaxial vilosa com tricomas sedosos ao tato; profilo persistente; nervuras secundárias partindo da nervura principal 5-6 surgindo da base até à porção mediana, direcionadas ao ápice; padrão de nervação eucamptódromo. Espiga 9-13 × 0,2-0,3 $\mathrm{cm}$, curva, raque glabra; pedúnculo $0,5-1,8 \mathrm{~cm}$ compr., pubescente; bráctea floral subtriangular, peltada, franjada, pilosa; flores sésseis; estames 4; ovário com estilete curto ou séssil, 3 estigmas. Fruto 0,9-1 × 0,8-1 mm, obovoide, ápice pubescente.

Material selecionado: Maricá, Morro da Serrinha, antigo túnel ferroviário, 28.V.2014, fl. e fr., G.A. de Queiroz et al. 144 (RB, RFFP). Niterói, Córrego dos Colibris, 10.III.2012, fl. e fr., G.A. de Queiroz et al. 32 (RB, RFFP); Morro do Telégrafo, Sítio do Céu, 19.II.2002, fr., A.A.M. de Barros et al. 1394 (RB, RFFP); Morrote do Vale dos Colibris, 10.III.2012, fl., G.A. de Queiroz et al. 27 (RB, RFFP); Vale das Borboletas, Trilha da Jararaca, 26.III.2013, fl., G.A. de Queiroz et al. 108 (RFFP).

Piper mollicomum é um arbusto ciófilo ou heliófilo extremamente abundante na Serra da Tiririca, habitando principalmente áreas antropizadas na borda de mata e beira de estradas. É facilmente reconhecido devido à forma de sua lâmina oblongo-elíptica, oblongo-lanceolada, além da pilosidade aveludada ao tato. Outro aspecto morfológico importante são suas inflorescências curvas. Esta espécie pode ser confundida facilmente com $P$. aduncum, mas difere por apresentar a face abaxial vilosa sedosa ao tato e a outra é escabra e áspera ao tato. Ilustração em Guimarães \& Valente (2001).

Ocorre na Colômbia, Venezuela e no Brasil, nas regiões Norte (Amazonas, Rondônia, Tocantins), Nordeste (Alagoas, Bahia, Ceará, Paraíba, Pernambuco), Centro-Oeste, Sudeste e Sul (Tebbs, 1993; W' ${ }^{3}$ Tropicos (Tropicos 2018);
Flora do Brasil 2020 (em construção).

Coletado florescendo nos meses de janeiro a março, maio, setembro a novembro e dezembro. Frutificando nos meses de fevereiro a junho, outubro.

11. Piper rivinoides Kunth, Prodr. 16(1): 312. 1869.

Fig. 10

Arbusto 1,6-3 m alt.; ramos 4-10 mm diâm., cilíndrico, estriados, lisos, glabros. Folhas com pecíolo 1,5-2 cm compr., estriado, canaliculado, glabro; bainha basal; lâmina 6-13,5 × 3-9 cm, discolor verde, papirácea, ovada, ovado-elíptica, translúcida, glândulas translúcidas esparsas, base simétrica, agudo-cuneado, ápice falcado, agudoacuminado, glabra em ambas as faces; profilo persistente; nervuras secundárias partindo da nervura principal 3-4 surgindo da base até o ápice, inseridas acima da base direcionadas às margens; padrão de nervação eucamptódromo. Espiga 4,5-7 $\times 0,3-0,5 \mathrm{~cm}$, ereta, raque glabra; pedúnculo $0,5-1$ $\mathrm{cm}$ de compr., glabro; bráctea floral triangular, peltada, às vezes, cuculada, glabra; flores sésseis; estames 3; ovário com estilete curto ou séssil; 3 estigmas. Fruto 1,3-1,5 × 1,2-1,5 mm, trigonal, glabro.

Material selecionado: Niterói, Enseada do Bananal, 14.VII.1997, fl. e fr., T.A. da Silva et al. 44 (RFFP); Morro do Telégrafo, Córrego dos Colibris, 10.III.2012, fr., G.A. de Queiroz et al. 34 (RB, RFFP).

Piper rivinoides é um arbusto ciófilo, que habita o interior da mata próximo à beira da trilha, margem de rios e locais úmidos. Reconhecido em campo pelas suas folhas brilhantes, ovadas, ovadoelíptica, inflorescências eretas e profilo persistente. Ilustração em Ichaso et al. (1977).

Espécie endêmica do Brasil ocorrendo nas regiões Norte (Amazonas, Pará), Nordeste (Bahia, Pernambuco), Centro-Oeste (Goiás), Sudeste (Espírito Santo, Minas Gerais, Rio de Janeiro, São Paulo) e Sul (Paraná, Santa Catarina) (W3 Tropicos (Tropicos 2018); Flora do Brasil 2020 (em construção).

Coletado florescendo no mês de maio e julho e frutificando nos meses de março a maio e julho.

12. Piper tuberculatum Jacq., Collectanea 2: 2. 1788.

Fig. $1 \mathrm{p}$

Arbusto ca. 1,5 m alt.; ramos 2-3 mm diâm., estriados, cilíndricos, verruculosos, glabro. Folhas com pecíolo 0,1-1 cm compr., estriado, verruculoso, alado, prolongado, projetando-se sobre a face adaxial da base da lâmina; bainha longa percorrendo toda 
a extensão do pecíolo; lâmina 4,1-8,5 × 1,8-3 cm, discolor verde, membranácea ou papirácea, oblonga, translúcida, eglandulosa, base assimétrica, cordada, um lado diferindo do outro 5-10 mm em relação ao outro lado, ápice obtuso, cuneado, glabra em ambas as faces com exceção das nervuras na face abaxial com tricomas; profilo caduco; nervuras secundárias partindo da nervura principal 8-10 inseridas desde a base atingindo o ápice da lâmina, direcionadas ao ápice; padrão de nervação broquidódromo. Espiga $5,3-6,2 \times 0,2 \mathrm{~cm}$, ereta, raque glabra; pedúnculo 0,8-1,8 cm compr., com tricomas; bráctea floral triangular, peltada, franjada, glabra; flores sésseis; estames 4; ovário com estilete curto ou séssil; 3 estigmas. Fruto $1-1,3 \times 1-1,2 \mathrm{~mm}$, tetragonal, achatado lateralmente, glabro.

Material examinado: Niterói, Córrego dos Colibris, 6.V.2017, fl. e fr., G.A. de Queiroz 420 (RB). Engenho do Mato, Rua São Sebastião, 2.VI.2017, fl. e fr., D.N.S. Machado \& T.S. Mendes 2118 (RFFP).

Piper tuberculatum é um arbusto ciófilo encontrado em área antropizada, facilmente registrado em canteiros de rua. Reconhecido em campo devido as suas folhas brilhantes, inflorescências eretas e ramos e pecíolos verruculosos. Ilustração em Tebbs (1989).

Ocorre em Belize, Bolívia, Brasil, Colômbia, Costa Rica, Equador, El Salvador, Estados Unidos, Guiana, Guiana Francesa, Guatemala, Honduras, Jamaica, México, Nicarágua, Panamá, Peru, Suriname, Trinidad e Venezuela. No Brasil ocorre em todas as regiões exceto nos estados do Amapá, Rio Grande do Sul, Santa Catarina e Sergipe (Trelease \& Yuncker 1950; Steyermark 1984; Tebbs 1989; W3 Tropicos (Tropicos 2018); Flora do Brasil 2020 (em construção).

Coletado florescendo e frutificando nos meses de maio e junho.

\section{Agradecimentos}

Agradecemos ao Conselho Nacional de Desenvolvimento Científico e Tecnológico (CNPq), a bolsa de Iniciação Científica concedida ao primeiro autor; aos colegas que auxiliaram nas coletas; e aos curadores dos herbários listados.

\section{Referências}

Andrade EHA, Guimarães EF \& Maia JGS (2009) Variabilidade química em óleos essenciais de espécies de Piper da Amazônia. FEQ/UFPA, Belém. $447 \mathrm{p}$.

APG IV - Angiosperm Phylogeny Group (2016) An update of the Angiosperm Phylogeny Group classification for the orders and families of flowering plants: APG IV. Botanical Journal of the Linnean Society 181: 1-20.

Barros AAM \& Pimentel DS (2010) Transformações ambientais e sociais aliadas à história de ocupação da Mata Atlântica no litoral do estado do Rio de Janeiro: o caso do Parque Estadual da Serra da Tiririca e arredores. In: Nodari ES, Klug J, Gerhardt M \& Moretto SP (orgs.) Simpósio Internacional de História Ambiental e Migrações. 1. Labimha, Florianópolis. Pp. 797-818.

Barros AAM \& Seoane CES (1999) A problemática da conservação do Parque Estadual da Serra da Tiririca, Niterói/Maricá, RJ, Brasil. In: Vallejo LR \& Silva MTC (orgs.) Os (des)caminhos do estado do Rio de Janeiro rumo ao século XXI. Instituto de Geociências da UFF, Niterói. Pp. 114-124.

Barros AAM, Ribas LA \& Araujo DSD (2009) Trepadeiras do Parque Estadual da Serra da Tiririca, Rio de Janeiro, Brasil. Rodriguésia 60: 681-694.

Callejas R (1986) Taxonomic Revision of Piper subgenus Ottonia (Piperaceae) South America. Tese de Doutorado. City University of New York, New York. 512p.

CRIA - Centro de Referência em Informação Ambiental (2018) SpeciesLink. Disponível em $<\mathrm{http}: / /$ splink. cria.org.br/>. Acesso em 08 outubro 2018.

Embrapa (2006) Sistema brasileiro de classificação de solos. $2^{\mathrm{a}}$ ed. Centro Nacional de Pesquisa de Solos, Rio de Janeiro. Pp. 306.

Flora do Brasil 2020 em construção (2018) Instituto de Pesquisas Jardim Botânico do Rio de Janeiro. Disponível em <http://floradobrasil.jbrj.gov.br/ reflora/floradobrasil/FB604533>. Acesso em 3 outubro 2018.

Frodin DG (2004) History and concepts of big plant genera. Taxon 53: 753-776.

Funk V, Hollowell T, Berry P, Kelloff C \& Alexander SN (2007) Checklist of the plants of the Guiana Shield (Venezuela: Amazonas, Bolivar, Delta Amacuro, Guyana, Suriname, French Guiana). Contributions from the United States National Herbarium 55: 1-584.

Greig N (1993) Regeneration mode in neotropical Piper: habitat and species comparisons. Ecology 74: 21252135.

Guedes-Bruni RR, Morim MP, Lima HC \& Sylvestre LS (2002) Inventário florístico. In: Sylvestre LS \& Rosa MMT (orgs.) Manual metodológico para estudos botânicos na Mata Atlântica. Universidade Rural, Seropédica. Pp. 24-50.

Guimarães EF (1994a) Piperaceae Organensis. Arquivos do Jardim Botânico do Rio de Janeiro 32: 50-106.

Guimarães EF (1994b) Piperaceae. In: Lima MP \& Guedes-Bruni RR (eds.) Reserva Ecológica de Macaé de Cima, Nova Friburgo, RJ. Aspectos florísticos das espécies Vasculares. Instituto de Pesquisas Jardim Botânico do Rio de Janeiro, Rio de Janeiro. 21p.

Guimarães EF, Carvalho-Silva M \& Cavalcanti TB (2007) Flora dos estados de Goiás e Tocantins: 
Piperaceae. Universidade Federal de Goiás, Goiânia. 68p.

Guimarães EF \& Giordano LCS (1997) Piperaceae CA Agardh. In: Marques MCM, Vaz ASF, Marquete R (eds.) Flórula da APA Cairuçu, Paraty, RJ: espécies vasculares. Série Estudos e Contribuições. Fundação Instituto de Pesquisas Jardim Botânico do Rio de Janeiro, Rio de Janeiro. Pp 396-439.

Guimarães EF \& Monteiro D (2006) Piperaceae na Reserva Biológica de Poço das Antas, Rio de Janeiro, Brasil. Rodriguésia 57: 569-589.

Guimarães EF \& Valente MC (2001) Piperáceas - Piper. In: Reitz R (org.) Flora Ilustrada Catarinense. Herbário Barbosa Rodrigues, Itajaí. 104p.

Ichaso CLF, Guimarães EF \& Costa CG (1977) Piperaceae do município do Rio de Janeiro - I. O gênero Piper L. Arquivos do Jardim Botânico do Rio de Janeiro 20: 145-188.

IINEA - Instituto Estadual do Ambiente do Rio de Janeiro (2015) Plano de Manejo (Fase 1). Parque Estadual da Serra da Tiririca. Disponível em <http://www. inea.rj.gov.br/wp-content/uploads/2019/02/PESETRE.pdf $>$. Acesso em 10 dezembro 2015.

Jaramillo MA, Manos PS \& Zimmer EA (2004) Phylogenetic relationships of the perianthless Piperales: reconstructing the evolution of floral development. International Journal of Plant Sciences 165: 403-416.

Kottek M, Grieser J, Beck C, Rudolf B \& Rubel F (2006) World map of the Köppen-Geiger climate classification updated. Meteorologische Zeitschrift 15: 259-263.

Miquel FAW (1852) Chloranthaceae et Piperaceae. In: CFP Martius \& AG Eichler (eds.). Flora brasiliensis. Lipsiae, Frid. Fleischer, v. 4, pars 1, pp. 1-76.

MMA - Ministério do Meio Ambiente (2015) Mata Atlântica. Disponível em <http://www.mma.gov. br/>. Acesso em 15 novembro 2015.

Monteiro D \& Guimarães EF (2009) Flora do Parque Nacional do Itatiaia - Brasil: Manekia e Piper (Piperaceae). Rodriguésia 60: 999-1024.

Penha HM (1999) A synthesis of geology of the east fluminense coast, state of Rio de Janeiro, Brazil. In: Knoppers BA, Bidone ED \& Abrão JJ (orgs.) Environmental geochemistry of coastal lagoon systems of Rio de Janeiro, Brazil. Universidade Federal Fluminense, Niterói. Pp. 3-10.
Pontes JAL (1987) Serra da Tiririca, RJ. Necessidade de conservação ( $1^{\text {a }}$ Contribuição). Boletim da Fundação Brasileira para a Conservação da Natureza 22: 89-94.

Queiroz GA (2017) Piperaceae do Leste Metropolitano, RJ, Brasil. Dissertação de Mestrado. Instituto de Pesquisas Jardim Botânico do Rio de Janeiro, Escola Nacional de Botânica Tropical, Rio de Janeiro. 237p.

Steyermark JA (1984) Flora de Venezuela, Piperaceae. Editorial Fundación Caracas, Caracas. Pp. 5-619.

Tebbs MC (1989) Revision of Piper (Piperaceae) in the New World 1. Review of characters and taxonomy of Piper section Macrostachys. Bulletin of the Natural History (Botany) 19: 117-158.

Tebbs MC (1990) Revision of Piper (Piperaceae) in the New World 2. The taxonomy of Piper section Churumayu. Bulletin of the Natural History (Botany) 20: 193-236.

Tebbs MC (1993) Piperaceae. In: Kubitzki K, Rohwer J G \& Bittrich V (eds). The families and genera of vascular plants II. Flowering plants; Dycotyledons: Magnoliid, Hamamelid and Caryophyliid families. Springer Verlag, Berlin. Pp. 516-520.

Thiers B [continuamente atualizado] Index Herbariorum: a global directory of public herbaria and associated staff. New York Botanical Garden's Virtual Herbarium. Disponível em $<$ http://sweetgum.nybg. org/science/ih/>. Acesso em 15 janeiro 2016.

Trelease W \& Yuncker TG (1950) The Piperaceae of Northern South America. 2 vols. University of Illinois Press, Urbana. 838p.

Wanke S, Samain MS, Vanderschaeva L, Mathieu G, Goetghebeur P \& Neinhuis C (2006) Phylogeny of the genus Peperomia (Piperaceae) inferred from the trnk/matk region (cpDNA). Plant Biology 8: 93-102.

Tropicos.org. Missouri Botanical Garden. Disponível em $<$ http://www.tropicos.org $>$ Acesso em 22 setembro 2018.

Yuncker TG (1950) Flora of Panama. Part IV, fascicle 1 - Piperaceae. Annals of the Missouri Botanical Garden 37: 1-120.

Yuncker TG (1972) The Piperaceae of Brazil I - Piper: Group I, II, III, IV. Hoehnea 2: 19- 366.

Yuncker TG (1973) The Piperaceae of Brazil II - Piper: Grupo V, Ottonia, Pothomorphe, Sarcorhachis. Hoehnea 3: 29-284. 


\section{Lista de exsicatas}

Alves BA \& Jascone CE 5 (8). Barros AAM 1034 (5.1), 1394 (10), 4554 (9), 650 (3). Barros AAM \& Coqueiro N 2468 (5.1). Barros AAM \& Moreira HP 1162 (2). Barros AAM \& Pinto LJS 1515 (2), 2781 (3). Barros AAM \& Santori RT 1946 (2). Barros AAM et al. 118 (8), 1541 (11), 1542 (11), 1952 (2), 1979 (3), 2135 (8), 2197 (6), 2245 (1), 2311 (2), 2330 (10). 2388 (8), 2448 (8), 2520 (8), 2661 (8), 2662 (8), 2663 (8), 2664 (8), 2746 (8), 2747 (1), 2768 (8), 3179 (3), 3187 (8), 3200 (2), 3202 (5.1), 3211 (8), 4241 (8), 4346 (1), 4376 (1), 4377 (3), 4548 (8), 4549 (9), 4572 (8), 4657 (1), 4663 (8), 5393 (3), 5415 (8), 5511 (3), 5514 (5.1), 5516 (10), 5517 (8), 5518 (5.1), 5530 (8). Carvalho WB et al. 230 (4), 237 (8), 207 (3). Coqueiro N 118 (2), 119 (6). Coqueiro N et al. 1 (3). Costa EV et al. 1 (2). Couto RS 335 (3). Feteira PW 207 (2). Feteira PW et al. 181 (3), 260 (10). Landum LR 4144 (2). Lemos AL 3 (10), 5 (3). Machado DNS 353 (10). Machado DNS \& Mendes TS 177 (2), 2118 (12). Machado DNS et al. 34 (6), 81 (8), 82 (3), 83 (10), 411 (5.2). 619 (8), 620 (5.1), 621 (5.2), 622 (8), 623 (10), 632 (8), 894 (8), 2031 (2). Machado TA et al. 1 (10). Marins TP et al. 1 (2). Matos VC et al. 18 (2). Melo J et al. 5 (2). Moreira HP 79 (3). Moreira HP et al. 78 (1). Moura SAA et al. 1 (3). Muritiba TAM et al. 1 (10), 35 (2). Pinto LJS 595 (2). Pinto LJS et al. 3 (3), 25 (3), 25 (3). Plowman TC 12861 (3). Queiroz GA 4 (2), 151 (8), 152 (11), 420 (12). Queiroz GA et al. 2 (2), 3 (9), 5 (2), 7 (8), 24 (5.1), 25 (8), 26 (10), 26 (10), 27 (10), 28 (2), 29 (3), 30 (3), 31 (8), 32 (10), 33 (3), 34 (11), 35 (2), 38 (3), 39 (2), 40 (3), 41 (8), 42 (2), 58 (8), 73 (5.1), 74 (10), 74 (10), 105 (5.2), 106 (2), 106 (2), 107 (3), $109(8), 110(11), 111(2), 112(10), 113(5.2), 114(3), 117$ (2), 118 (8), 119 (1), $143(5.1), 144$ (10), $145(2), 147(5.1), 148(5.1), 149$ (5.1), 150 (1), 154 (5.2), 268 (3), 269 (2), 270 (1), 271 (5.1), 272 (3), 273 (8), 274 (5.1), 283 (1), 335 (2), 336 (10), 337 (5.2), 340 (8), 342 (3), 351 (1), 352 (3), 353 (2), 354 (5.1), 355 (8), 382 (8), 383 (5.1). Ramos YJ 14 (1), 15 (10). Rosa P et al. 1114 (11). Santos LF 44 (3). Santos MCF et al. 65 (5.1), 232 (2). Santos MG et al. 1417 (11). Santos PT 48 (5.1), 75 (2). Santos PT et al. 37 (2), 75 (2), 87 (8). Silva RCC et al. 45 (5.1). Silva TA et al. 44 (11). Simonato E et al. 10 (1), 13 (10). Sousa LOF 321 (8), 330 (10). 